\title{
Application of Polyethylene Glycol to Promote Cellular Biocompatibility of Polyhydroxybutyrate Films
}

\author{
Rodman T. H. Chan, ${ }^{1}$ Helder Marçal, ${ }^{1}$ Robert A. Russell,, ${ }^{1,2}$ \\ Peter J. Holden, ${ }^{2}$ and L. John R. Foster ${ }^{1}$ \\ ${ }^{1}$ Bio/Polymer Research Group, Centre for Advanced Macromolecular Design, School of Biotechnology and Biomolecular Science, \\ University of New South Wales, Sydney, NSW 2052, Australia \\ ${ }^{2}$ Australian Nuclear Science \& Technology Organisation, Lucas Heights, Sydney, NSW 2234, Australia
}

Correspondence should be addressed to L. John R. Foster, j.foster@unsw.edu.au

Received 1 July 2011; Accepted 22 August 2011

Academic Editor: Shanfeng Wang

Copyright ( 2011 Rodman T. H. Chan et al. This is an open access article distributed under the Creative Commons Attribution License, which permits unrestricted use, distribution, and reproduction in any medium, provided the original work is properly cited.

Polyhydroxybutyrate (PHB) is a biomaterial with potential for applications in biomedical and tissue engineering; however, its brittle nature and high crystallinity limit its potential. Blending PHB with a variety of PEGs produced natural-synthetic composite films composed of FDA-approved polymers with significant reductions in crystallinity, from $70.1 \%$ for PHB films to $41.5 \%$ for its composite with a $30 \%(\mathrm{w} / \mathrm{w})$ loading of PEG2000. Blending also enabled manipulation of the material properties, increasing film flexibility with an extension to break of $2.49 \pm 1.01 \%$ for PHB films and $8.32 \pm 1.06 \%$ for films containing 30\% (w/w) PEG106. Significant changes in the film surface properties, as measured by porosity, contact angles, and water uptake, were also determined as a consequence of the blending process, and these supported greater adhesion and proliferation of neural-associated olfactory ensheathing cells (OECs). A growth rate of $7.2 \times 10^{5}$ cells per day for PHB films with $30 \%$ (w/w) PEG2000 loading compared to $2.5 \times 10^{5}$ for PHB films was observed. Furthermore, while cytotoxicity of the films as measured by lactate dehydrogenase release was unaffected, biocompatibility, as measured by mitochondrial activity, was found to increase. It is anticipated that fine control of PEG composition in PHB-based composite biomaterials can be utilised to support their applications in medicinal and tissue engineering applications.

\section{Introduction}

Polyhydroxybutyrate (PHB, Figure $1(\mathrm{a})$ ) is a semicrystalline biopolymer produced by a wide variety of bacteria when subjected to conditions of essential nutrient limitation with excess carbon $[1,2]$. The monomer component of microbial PHB, 3-hydroxybutyric acid (HBA), is recognised by mammalian enzymes; mammalian HBA is one of three ketone bodies and an essential source of mobile carbon for sufferers of starvation and diabetes mellitus [3]. Furthermore, the use of microbial HBA in mammals does not trigger any cytotoxic response [4]. First commercialised by W. R. Grace and Co. in the early 1950s, microbially produced PHB is an FDA- (Food and Drug Administration, USA) approved biomaterial investigated for application in a variety of medical devices $[5,6]$. For example, microbial PHB has been used as a nerve conduit to fill a $10 \mathrm{~mm}$ gap in injured sciatic nerve of Spague-Dawley rats and did not trigger any immune and inflammatory responses or cause anastomotic failures [7].

While PHB has a thermoplastic capability and a tensile strength comparable to polypropylene, its comparatively high crystallinity results in a brittle nature and relatively long degradation time under physiological conditions $[7,8]$. However, blending $\mathrm{PHB}$ with various additives provides a relatively simple and cost-effective opportunity to manipulate properties of PHB-based biomaterials [9].

PEG (Figure 1(b)) is an ideal candidate for blending with $\mathrm{PHB}$, a flexible polymer with good solubility in both water and organic solvents; it is used in protein purification processes, as well as a drug carrier and various other pharmaceutical applications $[10,11]$. A range of PEGs can be synthesised with average molecular weights (Mn) from 106 
(diethylene glycol, DEG) to 20,000. Also FDA-approved PEG is biocompatible with both blood and tissue, nontoxic to cellular system, nonimmunogenic, and an excellent conjugate for polymer graft materials $[12,13]$.

Blending PHB with polyethylene glycol (PEG) reduces crystallinity and other physiochemical properties of the composite biomaterial $[11,14]$. Tan et al. reported that PEG polymer chains remained mobile when PHB underwent crystallisation and moved to intra- and interspherulitic regions [15]. Thus, the presence of PEG in blends reduced the PHB crystallisation rate which promoted the formation of smaller spherulites and hindered nucleation; as a result, the PHB/PEG films became more flexible in comparison with their PHB counterparts. Zhang et al. reported that the crystallinity of PHB-based films decreased while their toughness was improved as the loading of PEG-20,000 increased from 10 to $20 \%(\mathrm{w} / \mathrm{w})$ [16]. Similarly, Rodrigues et al. demonstrated that PHB is completely miscible with PEG300 and the crystallinity was decreased as the PEG content increased in blends [17].

While there are a number of studies reporting blends of PHB with various PEGs, their focus has been on changes in crystallisation behaviour and subsequent physiochemical and material properties. In addition to blending, chemical grafting of PEG (PEGylation) to PHB and other members of the polyhydroxyalkanoate (PHA) family has also been investigated $[18,19]$. However, PEGylation reduces the molecular mass of the biopolymer to an extent where solubilisation may readily occur. More recently Foster and coworkers have shown that PEG-modulated biological synthesis of PHAs results in "endcapping" of the hydrophobic PHA chains with hydrophilic PEG molecules (bioPEGylation) [20]. While physiochemical and material changes due to bioPEGylation are comparatively minor, the presence of the covalently bound PEG groups promoted cell cycle progression in satellite stem cells [21]. In contrast to bioPEGylation, blending is a more simple process and provides greater flexibility in the loading and type of PEG that can be added. In the study here, we report on the influence of PEG loading and molecular mass on the physiochemical and material properties of PHB/PEG composite biomaterials. Furthermore, we report, for the first time, the influence that different PEG molecular weights and loadings has on cell adhesion and proliferation to PHB/PEG biomaterial films.

\section{Experimental}

2.1. Reagents. Polyhydroxybutyrate (PHB) of natural origin, polyethylene glycol (PEG) (molecular weights of 106, diethylene glycol (DEG) and 2000), and trypsin were purchased from Sigma Aldrich (Sydney, Australia). Analytical grade chloroform and dimethyl sulfoxide (DMSO) were purchased from Univar (Seven Hills, Australia). Mammalian cell growth medium, fetal bovine serum (FBS), and penicillin/streptococcus antibiotic were obtained from GibcoInvitrogen (Sydney, Australia). OECs were routinely cultured in Dulbecco's Modified Eagle's Medium (DMEM/F12) supplemented with 10\% FBS purchased from Lonza

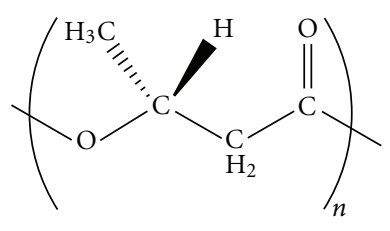

(a)

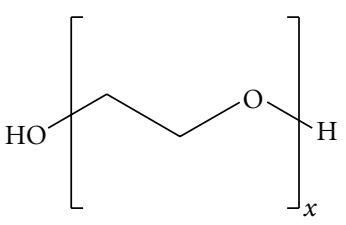

(b)
FIGURE 1: Chemical formulae for biomacromolecules (a) poly(3hydroxybutyrate): (PHB) and (b) poly(ethylene glycol): (PEG).

TABLE 1: Nomenclature of biomaterial films prepared in this study.

\begin{tabular}{lccc}
\hline Sample & \multicolumn{3}{c}{$\begin{array}{c}\text { Loading }(\% \mathrm{w} / \mathrm{w}) \\
\text { PEG106 }\end{array}$} \\
\hline PHB & 100 & 0 & PEG2000 \\
PHB/PEG106-10 & 90 & 10 & 0 \\
PHB/PEG106-20 & 80 & 20 & 0 \\
PHB/PEG106-30 & 70 & 30 & 0 \\
PHB/PEG2000-10 & 90 & 0 & 10 \\
PHB/PEG2000-20 & 80 & 0 & 20 \\
PHB/PEG2000-30 & 70 & 0 & 30 \\
\hline
\end{tabular}

(Portsmouth, NH, USA). CellTiter 96 aqueous one solution cell proliferation assay and in vitro lactic dehydrogenasebased toxicology kit were purchased from Promega (Madison, WI, USA) and Sigma Aldrich, respectively.

2.2. Film Fabrication. Biopolymer films were produced by solvent casting technique as described in the study by Rodrigues et al. [17]. Powdered PHB and PEG samples with respective weight ratios of $100: 0,90: 10,80: 20$, and $70: 30$ $(\mathrm{w} / \mathrm{w})$ were dissolved in heated chloroform in a sterile sealed vessel $\left(2 \% \mathrm{w} / \mathrm{v}, 160 \mathrm{rpm}, 50^{\circ} \mathrm{C}\right)$. The solution was allowed to $\operatorname{cool}\left(22^{\circ} \mathrm{C}, 160 \mathrm{rpm}, 15 \mathrm{mins}\right)$ before pouring into sterile, glass Petri dishes, and the solvent evaporated by standing ( 12 hours, $22^{\circ} \mathrm{C}$ ). The resulting films, labelled as per Table 1 , were subsequently maintained at $40^{\circ} \mathrm{C}$ under vacuum for 48 hours to remove any solvent residues.

2.3. Material Characterisation. Material properties of biopolymer films were analysed using a tensile testing instrument (Instron-5543, Norwood, MA, USA) at $22^{\circ} \mathrm{C}$ with $30 \%$ relative humidity. Films samples $(30 \times 15 \mathrm{~mm})$ were fixed using pneumatic grips of a calibrated tensile testing instrument and slowly moved apart $\left(20 \mathrm{~mm} \mathrm{~min}^{-1}\right)$. The maximum load, tensile strength, and extension at break were calculated using Bluehill computer software (Norwood, MA, USA). Means from at least ten samples were determined $(n=10)$.

The porosity of the biopolymer films were measured by ethanol displacement method [22]. The samples were cut into $50 \times 10 \mathrm{~mm}$ sizes and immersed in a measuring cylinder with a known volume of ethanol $\left(V_{1}\right)$. The total volume of ethanol and the films $\left(V_{2}\right)$ was recorded after 5 mins of immersion. The ethanol-impregnated film was removed, and the remaining ethanol volume was recorded $\left(V_{3}\right)$. Means of 
five samples were determined $(n=5)$. The porosity of the film was calculated by following formula:

$$
\text { Porosity }(\%)=\frac{\left(V_{1}-V_{3}\right)}{V_{2}-V_{3}} \times 100 \% \text {. }
$$

X-ray diffraction patterns of the biopolymer films were acquired using a Philips X'pert Material Research Diffraction (MRD) System (Eindhoven, Netherlands). Film samples (20 $\times 20 \mathrm{~mm}$ ) were secured on glass slides and aligned with $2 \theta, z$ axis, and omega scans (scattering angle range of $2 \theta=10-30^{\circ}$ and scan step size of $0.02^{\circ}$ continuous scan type). A radiation wavelength of $1.5406 \AA$ (Cu K-Alpha) was used to generate a power of $45 \mathrm{kV}$ and tube current of $40 \mathrm{~mA}$. The crystallinity (Xc) was calculated with the following equation and carried out using X'pert Highplus software and Excel software:

$$
\text { Crystallinity }(\%)=\left[\frac{F c}{F c+F a}\right] \times 100 \% \text {, }
$$

where $F c$ and $F a$ are the areas of crystal (peak) and noncrystal regions (under the curve), respectively.

Water uptake (WU) by the films was measured using gravimetry before and after water immersion [23]. The biopolymer films were cut into $40 \times 10 \mathrm{~mm}$ sizes and $20 \mu \mathrm{m}$ thickness, weighed, and immersed into $\mathrm{RO}$ water at $37^{\circ} \mathrm{C}$ for 50 mins $\left(W_{1}\right)$. The hydrated film was removed and weighed after drying the surface water with Kimwipes (Ringwood, Australia) $\left(W_{2}\right)$. The water uptake was calculated by the following formula:

$$
\mathrm{WU}(\%)=\frac{\left(W_{2}-W_{1}\right)}{W_{1}} \times 100 \%,
$$

where $\mathrm{WU}$ is the percentage of water uptake, $W_{1}$ and $W_{2}$ were the weight of sample film before and after immersion. Means of five samples were determined $(n=5)$.

The contact angle was measured by sessile drop method using contact angle meter at room temperature $\left(22^{\circ} \mathrm{C}, \mathrm{rH}\right.$ $30 \%$ ) to examine the hydrophilicity of polymer surface (KSV Cam 200, Espoo, Finland) [24]. Biopolymer films were cut into $40 \times 30 \mathrm{~mm}$ and microsyringed water droplets slowly allowed to fall onto their surfaces. Contact angles between the water droplet and the biopolymer films were recorded using KSV instrument software. Means of ten readings were calculated for each sample $(n=10)$.

2.4. Degradation Studies. Preweighed samples of biopolymer films $(30 \times 15 \mathrm{~mm})$ samples were sterilised through gammairradiation and placed into Eppendorf tubes $(2 \mathrm{~mL})$. Samples were incubated $\left(37^{\circ} \mathrm{C}, 150 \mathrm{rpm}\right)$ following the addition of $2 \mathrm{~mL}$ phosphate-buffered saline $(0.1 \mathrm{M}, \mathrm{pH} 7.4)$ with penicillin $\left(100\right.$ units $\left.\mathrm{mL}^{-1}\right)$, streptomycin $\left(100 \mu \mathrm{g} \mathrm{mL}^{-1}\right)$, and fungizone-amphotericin B $\left(2.5 \mu \mathrm{g} \mathrm{mL}^{-1}\right)$. At periodic intervals over an 84-day timescale, samples were removed, filtered, and dried in a dessicator $\left(40^{\circ} \mathrm{C}, 24 \mathrm{~h}\right)$ before allowing to acclimatise at $22^{\circ} \mathrm{C}$ (atmospherically equilibrated weight). The weight loss of the films was calculated with weight loss (\%), defined by (3):

$$
W(\%)=\frac{W_{t}}{W_{0}} \times 100 \%,
$$

where $W$ is the percentage weight loss, $W_{0}$ and $W_{t}$ were the initial weight and weight after incubation. Means of four samples per time point, per sample were determined $(n=4)$ [25].

2.5. Cell Studies. Murine olfactory ensheathing cells (OECs) were cultivated in medium consisting of DMEM, 10\% FBS, 250 unit penicillin, $250 \mu \mathrm{g} \mathrm{m}^{-1}$ streptomycin, and $1 \mu \mathrm{g} \mathrm{mL}^{-1}$ and fungizone-amphotericin B in T-75 tissue culture flasks incubated at $37^{\circ} \mathrm{C}$ with $5 \% \mathrm{CO}_{2}$ [26]. OECs were removed from the flask using trypsin $(2.5 \%)$ at $70 \%$ confluence. A cell population of approximately $4 \times 10^{4}$ cells $\mathrm{mL}^{-1}$ was used to inoculate films samples $(13 \times 13 \mathrm{~mm})$. At periodic intervals over a 10 -day timescale, samples were sacrificed and the films were twice rinsed with $10 \mathrm{~mL}$ of PBS; $2 \mathrm{~mL}$ of trypsin (2.5\%) was subsequently added before incubation $\left(37^{\circ} \mathrm{C}, 2\right.$ mins). Cell viability was then calculated using a haemocytometer and the trypan blue exclusion technique. Samples were conducted in triplicate $(n=3)$. Cell proliferation was also observed under a light microscope (Leica DFC 280, London, UK).

2.6. Microscopy. Film samples that had been cultivated with OECs were rinsed twice with $1 \%$ phosphate buffer saline (PBS) and fixed for four hours at $22^{\circ} \mathrm{C}$ in $2.5 \%$ glutaraldehyde in $0.1 \mathrm{M}$ PBS buffer ( $\mathrm{pH}$ 7.2). Subsequently, films were washed with PBS buffer three times for 5minute duration. After another buffer wash, samples were dehydrated for 10 minutes in a series of ethanol washes (30, 50, 70, 80, 90, 95, and 100\%) and critical point dried using liquid carbon dioxide. All specimens were mounted on aluminium stubs and surface coated with a layer of gold particles using a sputter coater (Emitech K550x, Ashford, England). Samples were subsequently examined using scanning electron microscopy (Hitachi S3400-I, Tokyo, Japan) at $15 \mathrm{kV}$ and $750 \mathrm{~mA}$, a procedure adapted from Chung et al. [27].

2.7. MTS Assay. Mitochondrial function in the OEC populations were assessed using a CellTiter 96 aqueous one solution cell proliferation assay [28]. OECs were cultured in DMEM with $10 \%$ FBS, harvested by trypsinisation, counted, and plated into 96-well plates with films of PHB, PHB/PEG106-20, PHB/PEG106-30, PHB/PEG2000-20, and PHB/PEG2000-30 (w/w). Cells cultivated in the absence of the biomaterials were used as control. 3000 cells were cultivated in each well and incubated for 48 hours $\left(37^{\circ} \mathrm{C}\right.$ with $5 \% \mathrm{CO}_{2}$ ); $30 \mu \mathrm{L}$ of MTS (3-(4,5-dimethylthiazol-2-yl)2,5-diphenyltetrazolium bromide) solution was then added to each well, and the plate incubated for a further 4 hours. MTS concentrations were determined at an absorbance of $490 / 690 \mathrm{~nm}$ using a microtitre plate spectrophotometer. A mean of 5 samples was determined $(n=5)$.

2.8. Lactate Dehydrogenase (LDH) Assay. LDH assays were used to detect cytotoxicity in the OECs population as a consequence of their incubation with $\mathrm{PHB}$ and $\mathrm{PHB} / \mathrm{PEG}$ films [29]. Cells were cultured in DMEM with 10\% FBS, harvested by trypsinisation, counted, and plated into 96-well 


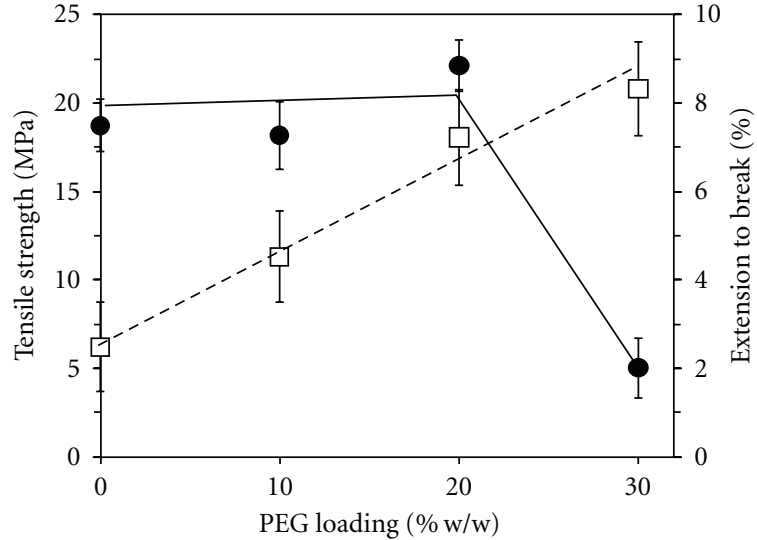

(a)

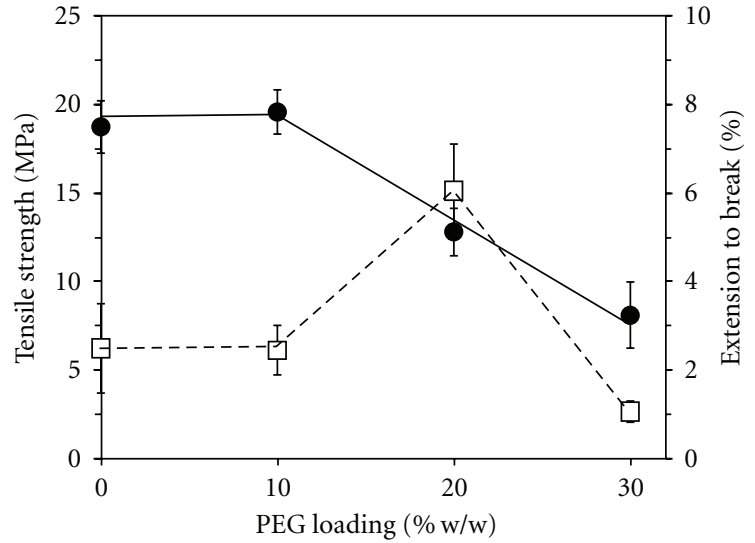

(b)

Figure 2: Change in material properties for PHB/PEG composite films with variations in PEG loading (\% w/w), (a) PEG106 and (b) PEG2000; $(\bullet)$ tensile strength $(\mathrm{MPa})$ and $(\square)$ extension to break $(\%)$.

plates with films of PHB, PHB/PEG106-20, PHB/PEG10630, PHB/PEG2000-20, and PHB/PEG2000-30. Cells cultivated in the absence of the biomaterials were used as healthy controls. 3,000 cells were cultivated in each well and incubated for 48 hours $\left(37^{\circ} \mathrm{C}, 5 \% \mathrm{CO}_{2}\right)$. At 45 minutes prior to the endpoint, $10 \mu \mathrm{L}$ samples of lysis solution were added to 5 of the wells and these served as positive controls. The plate was centrifuged for 5 minutes at $250 \mathrm{~g}$ at room temperature $\left(22^{\circ} \mathrm{C}, \mathrm{rH} 30 \%\right) .50 \mu \mathrm{L}$ samples of the supernatants were then transferred to a sterile 96 -well plate and $100 \mu \mathrm{L}$ of LDH mixture added to each well before incubating in the dark for 30 minutes $\left(37^{\circ} \mathrm{C}, 5 \% \mathrm{CO}_{2}\right) . \mathrm{LDH}$ analysis was performed at absorbances of 490 and $650 \mathrm{~nm}$ using microtitre plate spectrophotometer. Means of 5 samples were determined $(n=5)$.

2.9. Statistical Analysis. Mean values for data were calculated with standard deviation of each group. A Student's $t$-test was performed for significance with $95 \%$ confidence.

\section{Result and Discussion}

3.1. PHB/PEG Film Characterisation. Blending is recognised as a cost-effective technique for the manipulation of material and physiochemical properties of polymeric biomaterials. In the study here, the material properties of the solvent cast PHB films were similar to previous reports, with a tensile strength of $19 \pm 1.7 \mathrm{MPa}$ and extension to break of $2.5 \pm 1.8 \%$ [26]. While blending with up to $20 \%$ (w/w) PEG106 had no significant effect on the tensile strength of the PHB/PEG composite films, a loading of $30 \%(\mathrm{w} / \mathrm{w})$ (PHB/ PEG106-30) significantly reduced the strength to $5.2 \pm$ $1.9 \mathrm{MPa}$ (Figure 2(a), $P>0.005$ ). In contrast, the extension to break of the PHB/PEG106 films increased linearly to $8.3 \pm$ $1.1 \%$ with a $30 \%(\mathrm{w} / \mathrm{w})$ loading. As the molecular mass of the PEG was increased, the reduction in tensile strength PHB was observed after $10 \%(\mathrm{w} / \mathrm{w})$ PEG loading with a linear loss to $8.2 \pm 2.1 \mathrm{MPa}$ for PHB/PEG2000-30 films (Figure 2(b)). In

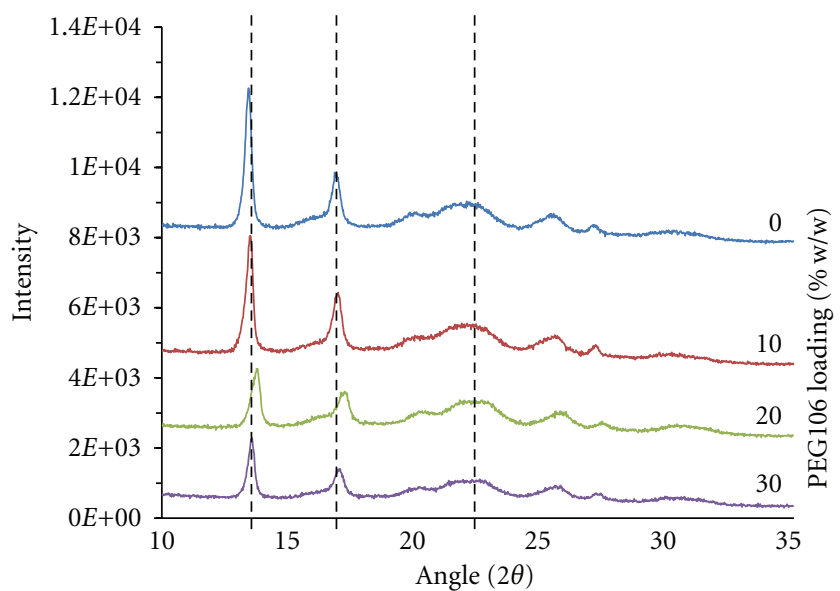

FIGURE 3: X-ray diffractograms of PHB/PEG composite films with variations in PEG106 loading (\% w/w).

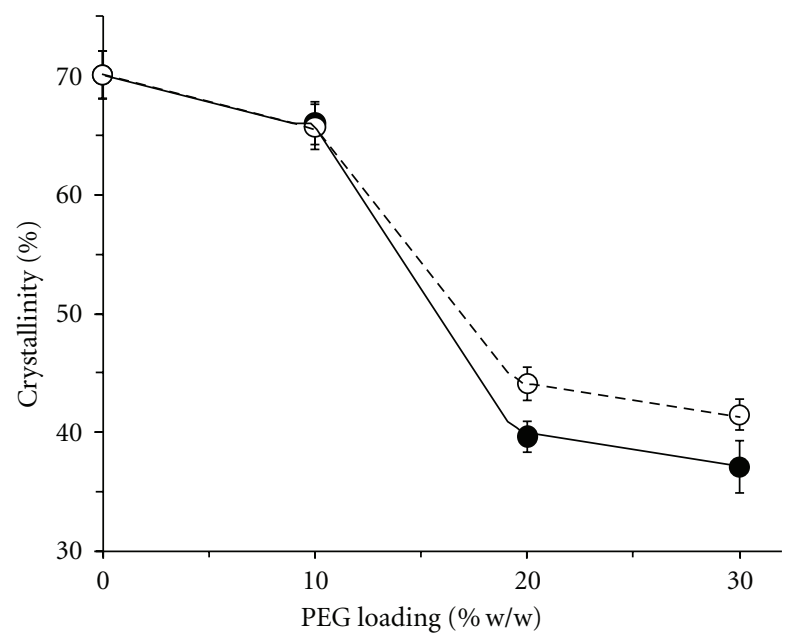

FIGURE 4: Change in crystallinity of PHB/PEG composite films with variations in PEG loading (\% w/w); (•) PEG106 and (०) PEG2000. 


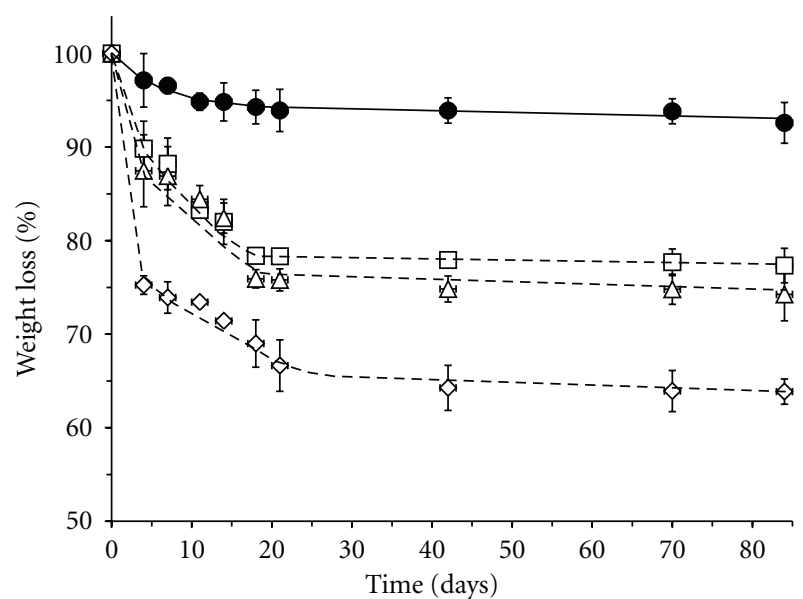

(a)

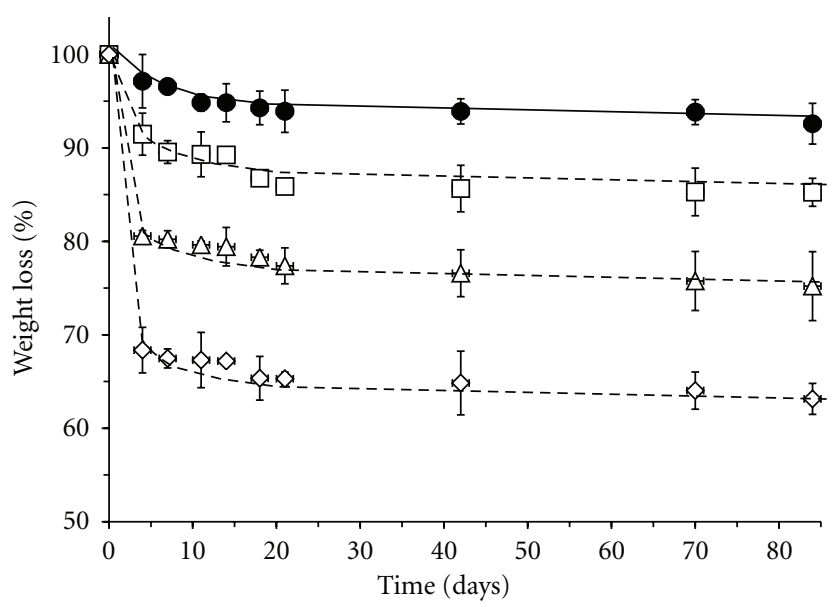

(b)

Figure 5: Change in weight loss profiles for PHB/PEG composite films with different PEG loadings (\% w/w) when incubated under

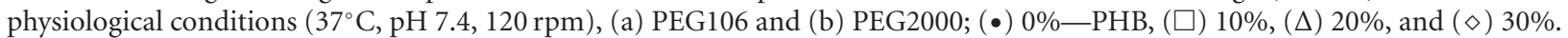

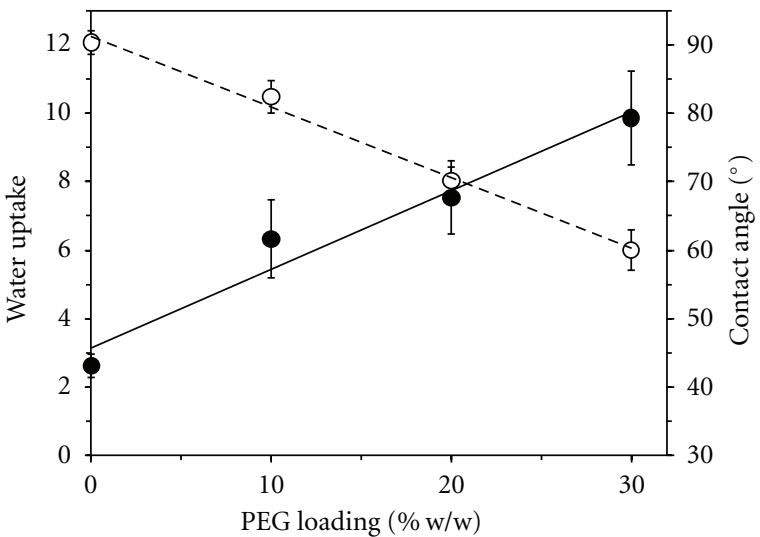

(a)

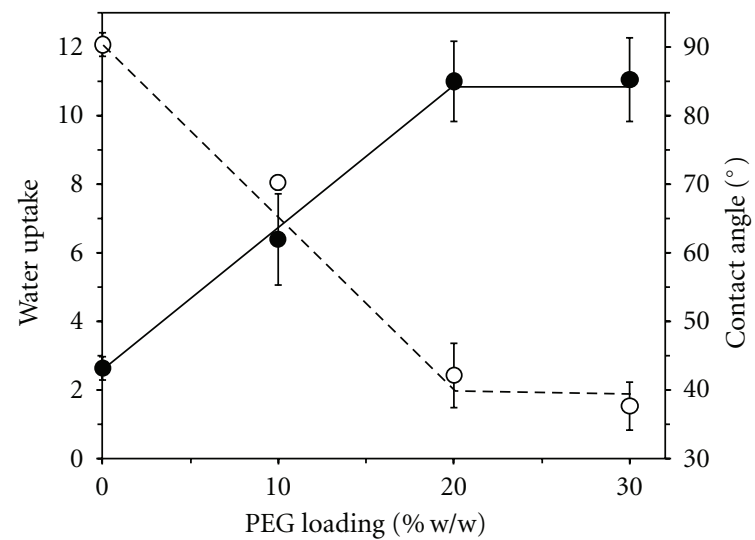

(b)

Figure 6: Change in water contact angles $(\bullet)$ and water uptakes $(\circ)$ for PHB/PEG composite films with different PEG loadings (\% w/w), (a) PEG106 and (b) PEG2000.

contrast to the blends with PEG106, PHB/PEG2000-20 films showed an increase in flexibility but decreased again as the PEG loading increased to $30 \%(\mathrm{w} / \mathrm{w})$. Thus, blending PHB with PEG generally increased the flexibility of the composite films when compared to the comparatively brittle PHB, with the changes being concentration dependent. The extension to break of both the PHB/PEG106-20 and PHB/PEG2000-20 films exhibited similar flexibilities to sutures fabricated from poly(tetrafluoroethylene) (PTFE), but was less flexible when compared to nylon and silk [30].

PHB is a semicrystalline biopolymer; the increases in extension to break of its composites with PEG suggest a change in crystallinity. X-ray diffraction patterns and maxima, observed at $14^{\circ}, 17^{\circ}$, and $22^{\circ}$ for PHB and PHB/PEG106 composite films, were found to be consistent with previous studies (Figure 3) [31]. As the PEG106 loading in the films increased, the intensity of the diffraction peaks was reduced (Figure 3). Similar X-ray diffraction patterns were also observed with the PHB/PEG2000 blends (data not shown). Consequently the crystallinity of the PHB/PEG films was observed to decrease from $70 \%$ for PHB films to approximately 45\% for films blended with 30\% (w/w) PEG106 and PEG2000, PHB/PEG106-30 and PHBPEG2000-30, respectively (Figure 4). The results suggest that the PHB crystal structure remained intact with separation of the crystalline PHB from amorphous PHB and DEG regions into semicrystalline matrices. Similar changes in PHB blends with cellulose acetate butyrate $(\mathrm{CAB})$ are reported by Wang et al. [32].

It is known that PHB has a relatively slow degradation rate under physiological conditions and blending has been used to manipulate its degradation behaviour [33]. In the study here, PHB films showed little weight loss after 84 days of incubation under the physiological conditions (Figure 5). In contrast, films with ascending PEG loadings exhibited significant weight losses only after 10 days (Figure 5). However, Figure 5 clearly shows that the initial weight loss approximated the initial PEG loadings; these losses occurred within 20 days of incubation for PHB/PEG106 films and 10 days for 


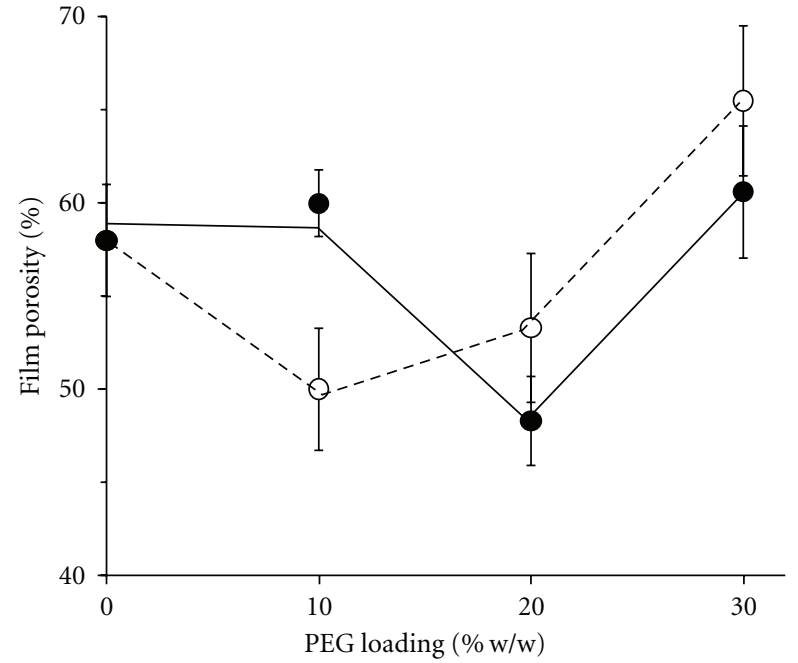

Figure 7: Change in porosity of PHB/PEG composite films with increasing PEG loading (\% w/w), (०) PEG106 and (•) PEG2000.

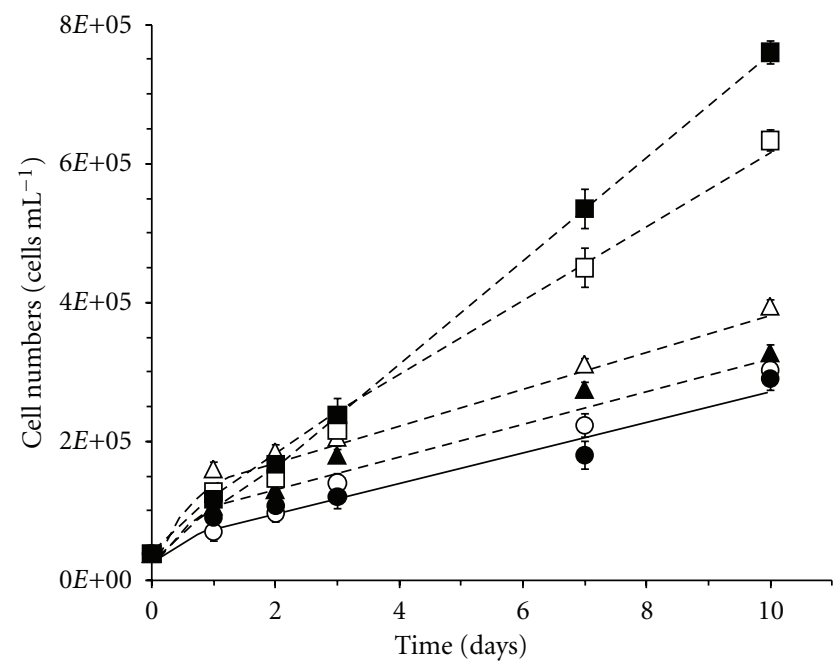

Figure 8: Change in growth of olfactory ensheathing cells (no. $\mathrm{mL}^{-1}$ ) when cultivated on PHB/PEG composite films with different PEG loadings (\% w/w); (०) cell culture dish, $(\bullet)$ PHB film, PHB/PEG106 films with $20(\Delta)$ and $30(\Delta) \%$ w/w loadings, PHB/ PEG2000 films with $20(\square)$ and $30(\mathbf{\square}) \%$ w/w loadings.

the PHB/PEG2000 films. Degradation of the residual films was negligible over the remaining duration of the study, consistent with the behaviour of PHB films (Figure 5) [34]. This initial dissolution of the relatively small, hydrophilic PEG groups from the hydrophobic PHB matrix is consistent with previous studies of PHB-pectin composites, where the relatively smaller pectin was solubilised and released from within PHB films [35]. Initial dissolution of the pectin was shown to subsequently promote weight loss of the remaining PHB film after a plateau period of apparent stability.

PHB is a hydrophobic biopolymer with films here exhibiting a water contact angle of $90.3 \pm 1.7^{\circ}$; blending with PEG106 reduced the contact angles of the composites films in a linear fashion, with PHB/PEG106-30 possessing an angle of $60.0 \pm 3.0^{\circ}$ (Figure 6) [24]. Thus, blending PEG with PHB can improve the hydrophilicity of the films, and this was evident with an increase in water uptake, from $2.62 \pm 0.34 \%$ for PHB to $9.86 \pm 1.37 \%$ for PHB/PEG10630 (Figure 6(a)). PEG of a higher molecular weight had a proportional greater influence on the hydrophilicity of the composite films, a linear decrease in water contact angle with increasing PEG2000 loading occurred to 20\% loading before stabilising at approximately $39^{\circ}$ (Figure 6(b)). Similarly, the water uptake increased to a maximum of $11.04 \pm 1.22 \%$ for PHB/PEG2000-30. A number of studies have suggested that the hydrophilic-hydrophobic relationship on biomaterial surfaces to influence cellular adhesion and proliferation [36].

Consistent with previous reports, PHB films in this study had a porosity of $58 \pm 3.0 \%$ [33]. Blending the PHB with PEG resulted in slight but significant changes to the porosity of the films, ranging from $48.3 \pm 4.0 \%$ for PHB/PEG106-20 films to $65.5 \pm 3.6 \%$ for PHB/PEG2000-30 films as illustrated in Figure 7. Saad et al. have shown that osteoblasts tend to attach and grow into the pores and grooves of a highly porous scaffold, suggesting that surface porosity had an important role in cell attachment [37]. Increases in porosity of the PHBbased biomaterials have also been shown to accelerate its physiological degradation rate [38]. Thus, surface properties reported to influence cell attachment could be adjusted in PHB films by blending with PEGs of different molecular weights and loadings.

3.2. Cellular Responses to the PHB/PEG Films. Consistent with changes to the composite surface properties, adult olfactory ensheathing cells (OECs) cultivated on the films showed significant changes in attachment and proliferation (Figure 8). The growth patterns of OECs on the polystyrene tissue culture plate (control) were similar to those of the PHB films with steady increases over a ten-day incubation period. Blending with PEG106 increased the initial cell attachment although their subsequent growth rates were similar to those cultivated on PHB. In contrast, blending with PEG2000 had a much greater influence, with PHB/PEG2000-30 exhibiting a growth rate of $7.2 \times 10^{5}$ cells $\mathrm{mL}^{-1}$ per day compared to 2.7 $\times 10^{5}$ cells mL $\mathrm{mL}^{-1} \mathrm{dy}^{-1}$ for PHB/PEG106-30 and $2.5 \times 10^{5}$ cells $\mathrm{mL}^{-1} \mathrm{dy}^{-1}$ for PHB films (Figure 8). Thus, blending with PEG promoted the growth of OECs on the PHB-based composite films.

PEG, or its high molecular weight equivalent, polyethylene oxide (PEO), can be used to develop protein-repelling surfaces. Consequently, PEG has been incorporated onto biomaterial surfaces through grafting [39], adsorption surface treatments [40], and through bulk incorporation via crosslinking [41] or block copolymerization [42]. The design of most PEG-derivatized surfaces has sought to eliminate cell and protein adhesion using high PEG surface concentrations. However, Tziampazis et al. have suggested that the conformation of the adhered proteins can also play a crucial role in determining cell adhesion and proliferation and have used small surface concentrations of PEG to regulate cell adhesion and differentiation [42]. Furthermore, Zhang et al. have clearly shown that blending with PEG effectively improved 


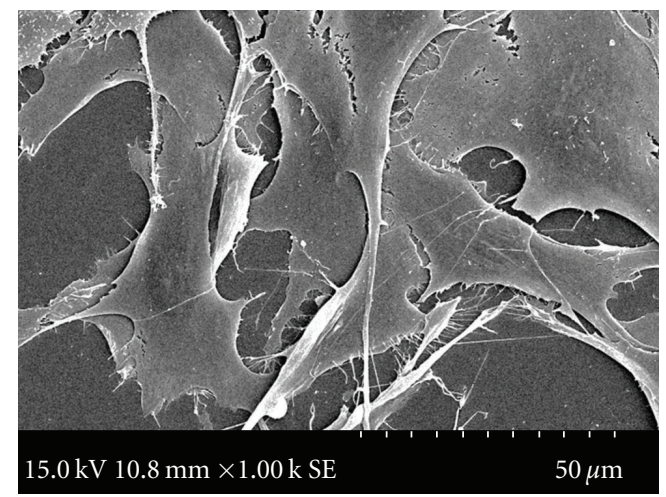

(a)

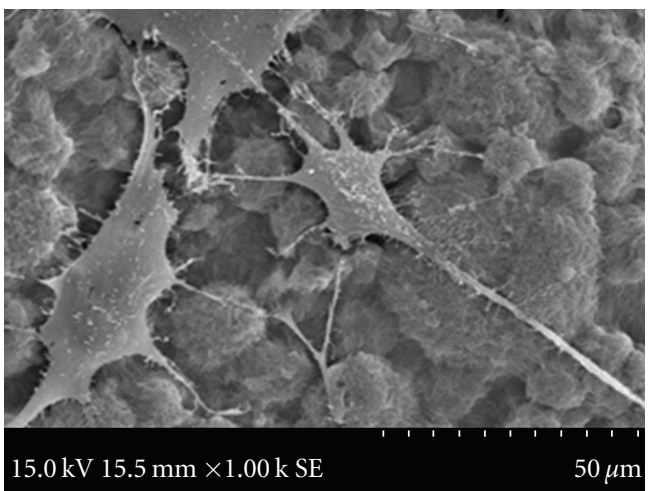

(c)

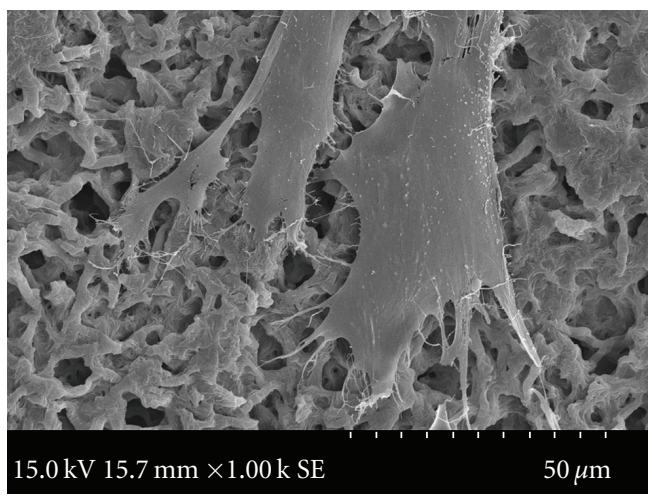

(b)

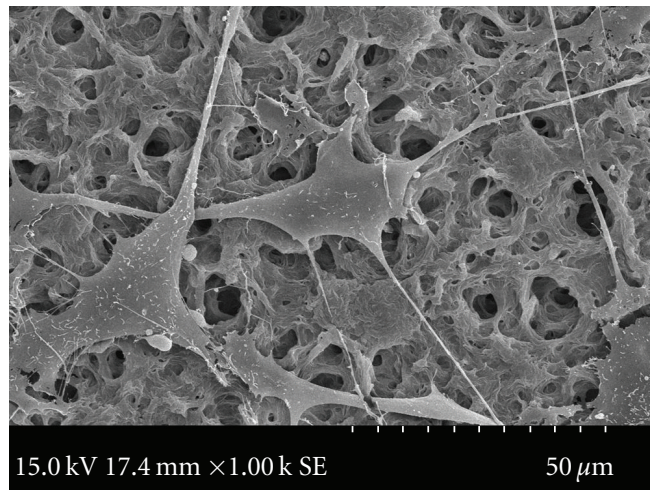

(d)

FIGURE 9: Scanning electron micrographs illustrating morphology of olfactory ensheathing cells attached to various surfaces after 24 hours of cultivation: (a) Polystyrene slide, (b) PHB film, (c) PHB/PEG106 with 20\% w/w loading, and (d) PHB/PEG2000 with 20\% w/w loading.

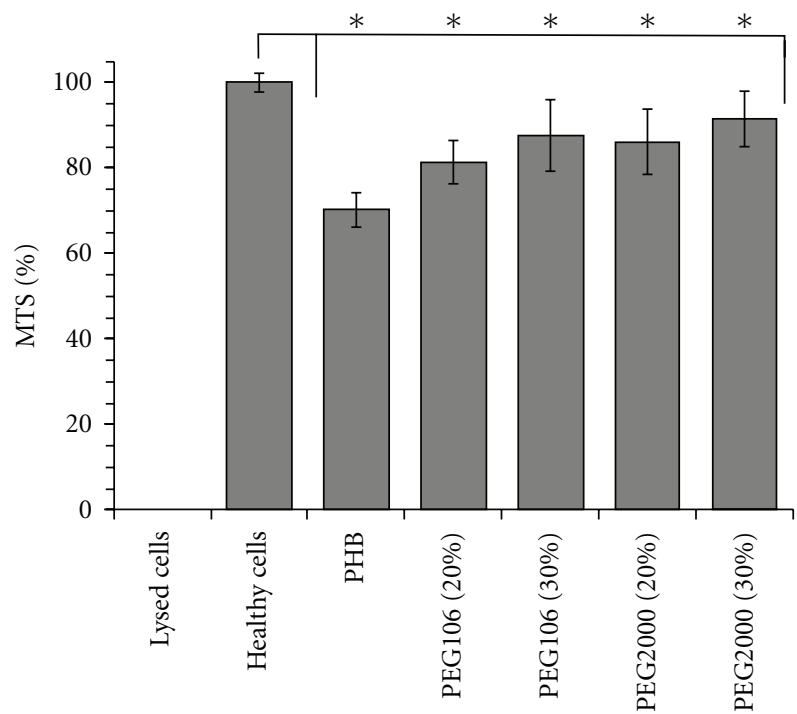

(a)

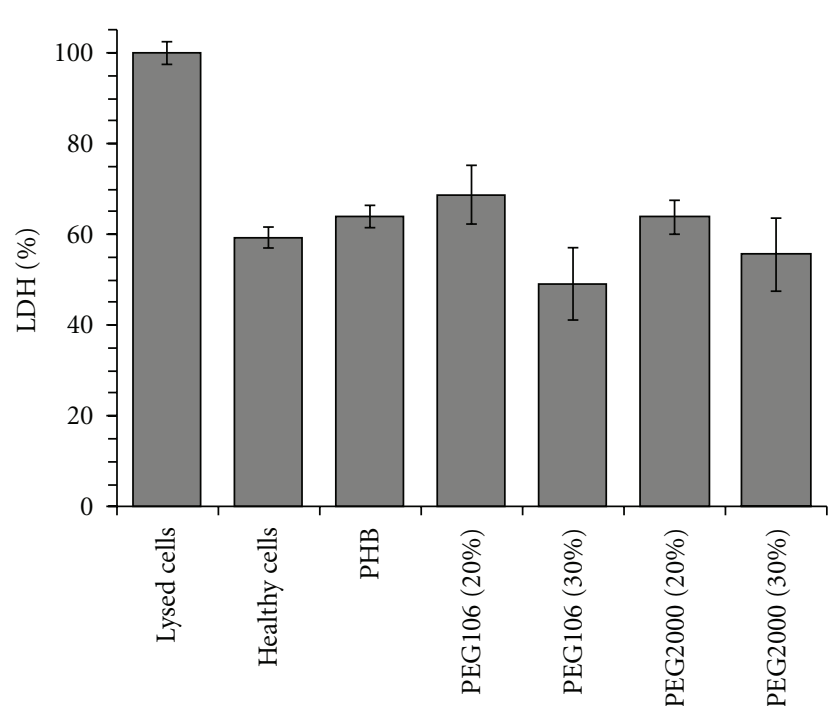

(b)

FIGURE 10: Changes in cellular activity relative to healthy cells, for olfactory ensheathing cells cultivated on PHB and PHB/PEG composite films: (a) MTS concentrations and (b) LDH release $\left({ }^{*} P>0.005\right.$ significance, $\left.n=10\right)$. 
the biocompatibility of chitosan films [43]. Thus, in the solvent evaporated $\mathrm{PHB} / \mathrm{PEG}$ blends reported here, one can speculate that the bulk of the PEG was used to modify the material properties while small surface concentrations enhanced cell adhesion and proliferation.

Qualitative examination of OECs attached to the films showed revealed no abnormal cell morphology. The healthy cells appeared flat with many filopodial extensions (Figure 9). These filopodia play an important role in neuron regeneration, which is the first step in growth cone formation [44]. Ahmed et al. have also reported that the actin-containing filopodial extensions in OECs cultivated on PHB films provided cell mobility and greater cell-cell communication [45]. Over three days of incubation, OECs proliferated profusely consistent with the control (Figure 9).

The MTS assay measures the mitochondrial activity of the cells by reducing the substrate, yellow MTS tetrazolium salt into purple formazan compound and can be used as an indicator of cell viability [45]. In the study here, the percentages of MTS for cells cultivated on the PHB and $\mathrm{PHB} / \mathrm{PEG}$ composite films were significantly different when compared to a control of healthy cells. Furthermore, OECs grown on the PHB/PEG composite films exhibited MTS levels closer to that exhibited by the control of healthy cells than the cells grown on PHB films $(P>0.005$, Figure 10(a)). When under stress cell membranes exhibit increased permeability and a subsequent release of lactate dehydrogenase $(\mathrm{LDH}) . \mathrm{LDH}$ in the cultivation medium provides an indication of cellular cytotoxicity [28]. In the study here, the concentration of $\mathrm{LDH}$ released from cells cultivated on the $\mathrm{PHB}$ and $\mathrm{PHB} / \mathrm{PEG}$ composite films was statistically similar to healthy cells $(P>0.005$, Figure 10$)$. The results suggest that none of the films investigated were cytotoxic; however, blending with PEG enhanced cell viability. Thus, the presence of PEG in the PHB films supported initial attachment of OECs and their subsequent proliferation despite the PEGs being released from the biopolymer matrices within the first 5 days of incubation.

\section{Conclusions}

The biopolymer $\mathrm{PHB}$ is an FDA-approved biomaterial; however, its relatively high crystallinity and brittle nature greatly reduce its potential for application in biomedical devices. Blending is a cost-effective and comparatively simple technique to modify the final properties of PHB-based composites. Blending $\mathrm{PHB}$ with a variety of PEGs produced natural-synthetic composite films composed of FDA-approved polymers with significant reductions in crystallinity and enabled manipulation of the material properties and degradation potential of the composites. Flexibility of the $\mathrm{PHB} / \mathrm{PEG}$ composite films was improved compared to PHB, as was the hydrophilicity. Changes to surface morphology and hydrophilicity were found to increase the attachment and proliferation of OECs promoting the biocompatibility of the composite biomaterials compared to PHB. It is anticipated that fine control of PEG composition in PHBbased composite biomaterials can be utilised to support their applications in medicinal and tissue engineering applications.

\section{References}

[1] F. M. Kapritchkoff, A. P. Viotti, R. C. P. Alli et al., "Enzymatic recovery and purification of polyhydroxybutyrate produced by Ralstonia eutropha," Journal of Biotechnology, vol. 122, no. 4, pp. 453-462, 2006.

[2] H. Mitomo, W. -C. Hsieh, K. Nishiwaki, K. Kasuya, and Y. Doi, "Poly(3-hydroxybutyrate-co-4-hydroxybutyrate) produced by Comamonas acidovorans," Polymer, vol. 42, no. 8, pp. 34553461, 2001.

[3] X. Hang, Z. Lin, J. Chen, G. Wang, K. Hong, and G. Q. Chen, "Polyhydroxyalkanoate biosynthesis in Pseudomonas pseudoalcaligenes YS1," FEMS Microbiology Letters, vol. 212, no. 1, pp. 71-75, 2002.

[4] L. J. R. Foster and B. J. Tighe, "Enzymatic assay of hydroxybutyric acid monomer formation in poly( $\beta$-hydroxybutyrate) degradation studies," Biomaterials, vol. 16, no. 4, pp. 341-343, 1995.

[5] M. Zinn, B. Witholt, and T. Egli, "Occurrence, synthesis and medical application of bacterial polyhydroxyalkanoate," Advanced Drug Delivery Reviews, vol. 53, no. 1, pp. 5-21, 2001.

[6] P. Vandamme and T. Coenye, "Taxonomy of the genus Cupriavidus: a tale of lost and found," International Journal of Systematic and Evolutionary Microbiology, vol. 54, no. 6, pp. 22852289, 2004.

[7] S. Philip, T. Keshavarz, and I. Roy, "Polyhydroxyalkanoates: biodegradable polymers with a range of applications," Journal of Chemical Technology and Biotechnology, vol. 82, no. 3, pp. 233-247, 2007.

[8] I. M. Arcana, A. Sulaeman, K. D. Pandiangan, A. Handoko, and M. Ledyastuti, "Synthesis of polyblends from polypropylene and $\operatorname{poly}(\mathrm{R}, \mathrm{S})-\beta$-hydroxybutyrate, and their characterization," Polymer International, vol. 55, no. 4, pp. 435-440, 2006.

[9] C. Chen, X. Zhou, Y. Zhuang, and L. Dong, "Thermal behavior and intermolecular interactions in blends of poly(3hydroxybutyrate) and maleated poly(3-hydroxybutyrate) with chitosan," Journal of Polymer Science Part B: Polymer Physics, vol. 43, no. 1, pp. 35-47, 2005.

[10] J. M. Harris, Poly (Ethylene Glycol) Chemistry: Biotechnical and Biomedical Applications, Plenum Press, New York, NY, USA, 1992.

[11] G. X. Cheng, T. Z. Wang, Q. Zhao, X. L. Ma, and L. G. Zhang, "Preparation of cellulose acetate butyrate and poly(ethylene glycol) copolymers to blend with poly(3-hydroxybutyrate)," Journal of Applied Polymer Science, vol. 100, pp. 1471-1478, 2006.

[12] X. Li, K. L. Liu, J. Li et al., "Synthesis, characterization, and morphology studies of biodegradable amphiphilic poly[(R)-3-hydroxybutyrate]-alt-poly(ethylene glycol) multiblock copolymers," Biomacromolecules, vol. 7, no. 11, pp. 3112-3119, 2006.

[13] S. Zalipsky, "Synthesis of an end-group functionalized polyethylene glycol-lipid conjugate for preparation of polymer-grafted liposomes," Bioconjugate Chemistry, vol. 4, no. 4, pp. 296-299, 1993.

[14] R. D. Ashby, F. Shi, and R. A. Gross, "Use of poly(ethylene glycol) to control the end group structure and molecular weight of poly(3-hydroxybutyrate) formed by Alcaligenes latus DSM 1122," Tetrahedron, vol. 53, no. 45, pp. 15209-15223, 1997. 
[15] S. M. Tan, J. Ismail, C. Kummerlöwe, and H. W. Kammer, "Crystallization and melting behavior of blends comprising poly(3-hydroxy butyrate-co-3-hydroxy valerate) and poly(ethylene oxide)," Journal of Applied Polymer Science, vol. 101, no. 5, pp. 2776-2783, 2006.

[16] Q. Zhang, Y. Zhang, F. Wang, L. Liu, and C. Wang, "Thermal properties of PHB/PEG blends," Journal of Materials Science and Technology, vol. 14, no. 1, pp. 95-96, 1998.

[17] J. A.F.R. Rodrigues, D. F. Parra, and A. B. Lugão, "Crystallization on films of PHB/PEG blends evaluation by DSC," Journal of Thermal Analysis and Calorimetry, vol. 79, no. 2, pp. 379381, 2005.

[18] L. J. R. Foster, "Biosynthesis, properties and potential of natural-synthetic hybrids of polyhydroxyalkanoates and polyethylene glycols," Applied Microbiology and Biotechnology, vol. 75, no. 6, pp. 1241-1247, 2007.

[19] B. Hazer and A. Steinbüchel, "Increased diversification of polyhydroxyalkanoates by modification reactions for industrial and medical applications," Applied Microbiology and Biotechnology, vol. 74, no. 1, pp. 1-12, 2007.

[20] V. Sanguanchaipaiwong, C. L. Gabelish, J. Hook, C. Scholz, and L. J. R. Foster, "Biosynthesis of natural-synthetic hybrid copolymers: polyhydroxyoctanoate-diethylene glycol," Biomacromolecules, vol. 5, no. 2, pp. 643-649, 2004.

[21] H. Marçal, N. S. Wanandy, V. Sanguanchaipaiwong et al., "BioPEGylation of polyhydroxyalkanoates: influence on properties and satellite-stem cell cycle," Biomacromolecules, vol. 9, no. 10, pp. 2719-2726, 2008.

[22] R. Zhang and P. X. Ma, "Poly( $\alpha$-hydroxyl acids)/hydroxyapatite porous composites for bone- tissue engineering. I. Preparation and morphology," Journal of Biomedical Materials Research, vol. 44, no. 4, pp. 446-455, 1999.

[23] X. Li, K. L. Liu, M. Wang et al., "Improving hydrophilicity, mechanical properties and biocompatibility of poly[(R)-3hydroxybutyrate-co-(R)-3-hydroxyvalerate] through blending with poly[(R)-3-hydroxybutyrate]-alt-poly(ethylene oxide)," Acta Biomaterialia, vol. 5, no. 6, pp. 2002-2012, 2009.

[24] K. J. Townsend, K. Busse, J. Kressler, and C. Scholz, "Contact angle, WAXS, and SAXS analysis of poly( $\beta$-hydroxybutyrate) and poly(ethylene glycol) block copolymers obtained via Azotobacter vinelandii UWD," Biotechnology Progress, vol. 21, no. 3, pp. 959-964, 2005.

[25] T. Freier, C. Kunze, C. Nischan et al., "In vitro and in vivo degradation studies for development of a biodegradable patch based on poly(3-hydroxybutyrate)," Biomaterials, vol. 23, no. 13, pp. 2649-2657, 2002.

[26] T. Ahmed, H. Marçal, M. Lawless, N. S. Wanandy, A. Chiu, and L. J. R. Foster, "Polyhydroxybutyrate and its copolymer with polyhydroxyvalerate as biomaterials: influence on progression of stem cell cycle," Biomacromolecules, vol. 11, no. 10, pp. 2707-2715, 2010.

[27] R. S. Chung, A. Woodhouse, S. Fung et al., "Olfactory ensheathing cells promote neurite sprouting of injured axons in vitro by direct cellular contact and secretion of soluble factors," Cellular and Molecular Life Sciences, vol. 61, no. 10, pp. 1238-1245, 2004.

[28] L. Braydich-Stolle, S. Hussain, J. J. Schlager, and M. C. Hofmann, "In vitro cytotoxicity of nanoparticles in mammalian germline stem cells," Toxicological Sciences, vol. 88, no. 2, pp. 412-419, 2005.

[29] C. Y. Xia, C. X. Yuan, and C. G. Yuan, "Galanin inhibits the proliferation of glial olfactory ensheathing cells," Neuropeptides, vol. 39, no. 5, pp. 453-459, 2005.
[30] J. M. Garcia Paez, A. Carrera San Martin, J. V. Garcia Sestafe et al., "Resistance and elasticity of the suture threads employed in cardiac bioprostheses," Biomaterials, vol. 15, no. 12, pp. 981984, 1994.

[31] B. L. Hurrell and R. E. Cameron, "A wide-angle X-ray scattering study of the ageing of poly(hydroxybutyrate)," Journal of Materials Science, vol. 33, no. 7, pp. 1709-1713, 1998.

[32] T. Wang, G. Cheng, S. Ma, Z. Cai, and L. Zhang, "Crystallization behavior, mechanical properties, and environmental biodegradability of poly $(\beta$-hydroxybutyrate)/cellulose acetate butyrate blends," Journal of Applied Polymer Science, vol. 89, no. 8, pp. 2116-2122, 2003.

[33] C. W. Pouton and S. Akhtar, "Biosynthetic polyhydroxyalkanoates and their potential in drug delivery," Advanced Drug Delivery Reviews, vol. 18, no. 2, pp. 133-162, 1996.

[34] L. J. R. Foster and B. J. Tighe, "Centrifugally spun polyhydroxybutyrate fibres: accelerated hydrolytic degradation studies," Polymer Degradation and Stability, vol. 87, no. 1, pp. 1-10, 2005.

[35] L. J. R. Foster and B. J. Tighe, "In vitro hydrolytic degradation of centrifugally spun polyhydroxybutyrate-pectin composite fibres," Polymer International, vol. 58, no. 12, pp. 1442-1451, 2009.

[36] Z. Kai, D. Ying, and C. Guo-Qiang, "Effects of surface morphology on the biocompatibility of polyhydroxyalkanoates," Biochemical Engineering Journal, vol. 16, no. 2, pp. 115-123, 2003.

[37] B. Saad, P. Neuenschwander, G. K. Uhlschmid, and U. W. Suter, "New versatile, elastomeric, degradable polymeric materials for medicine," International Journal of Biological Macromolecules, vol. 25, no. 1-3, pp. 293-301, 1999.

[38] G. Q. Chen and Q. Wu, "The application of polyhydroxyalkanoates as tissue engineering materials," Biomaterials, vol. 26, no. 33, pp. 6565-6578, 2005.

[39] B. Wesslen, M. Kober, C. Freij-Larsson, A. Ljungh, and M. Paulsson, "Protein adsorption of poly(ether urethane) surfaces modified by amphiphilic and hydrophilic polymers," Biomaterials, vol. 15, no. 4, pp. 278-284, 1994.

[40] K. Bergstrom, K. Holmberg, A. Safranj et al., "Reduction of fibrinogen adsorption on PEG-coated polystyrene surfaces," Journal of Biomedical Materials Research, vol. 26, no. 6, pp. 779-790, 1992.

[41] P. D. Drumheller and J. A. Hubbell, "Densely crosslinked polymer networks of poly(ethylene glycol) in trimethylolpropane triacrylate for cell-adhesion-resistant surfaces," Journal of Biomedical Materials Research, vol. 29, no. 2, pp. 207-215, 1995.

[42] E. Tziampazis, J. Kohn, and P. V. Moghe, "PEG-variant biomaterials as selectively adhesive protein templates: model surfaces for controlled cell adhesion and migration," Biomaterials, vol. 21, no. 5, pp. 511-520, 2000.

[43] M. Zhang, X. H. Li, Y. D. Gong, N. M. Zhao, and X. F. Zhang, "Properties and biocompatibility of chitosan films modified by blending with PEG," Biomaterials, vol. 23, no. 13, pp. 26412648, 2002.

[44] M. Hammarlund, P. Nix, L. Hauth, E. M. Jorgensen, and M. Bastiani, "Axon regeneration requires a conserved MAP kinase pathway," Science, vol. 323, no. 5915, pp. 802-806, 2009.

[45] T. Ahmed, H. Marçal, M. Lawless, N. S. Wanandy, A. Chiu, and L. J. R. Foster, "Polyhydroxybutyrate and its copolymer with polyhydroxyvalerate as biomaterials: influence on progression of stem cell cycle," Biomacromolecules, vol. 11, no. 10, pp. 2707-2715, 2010. 

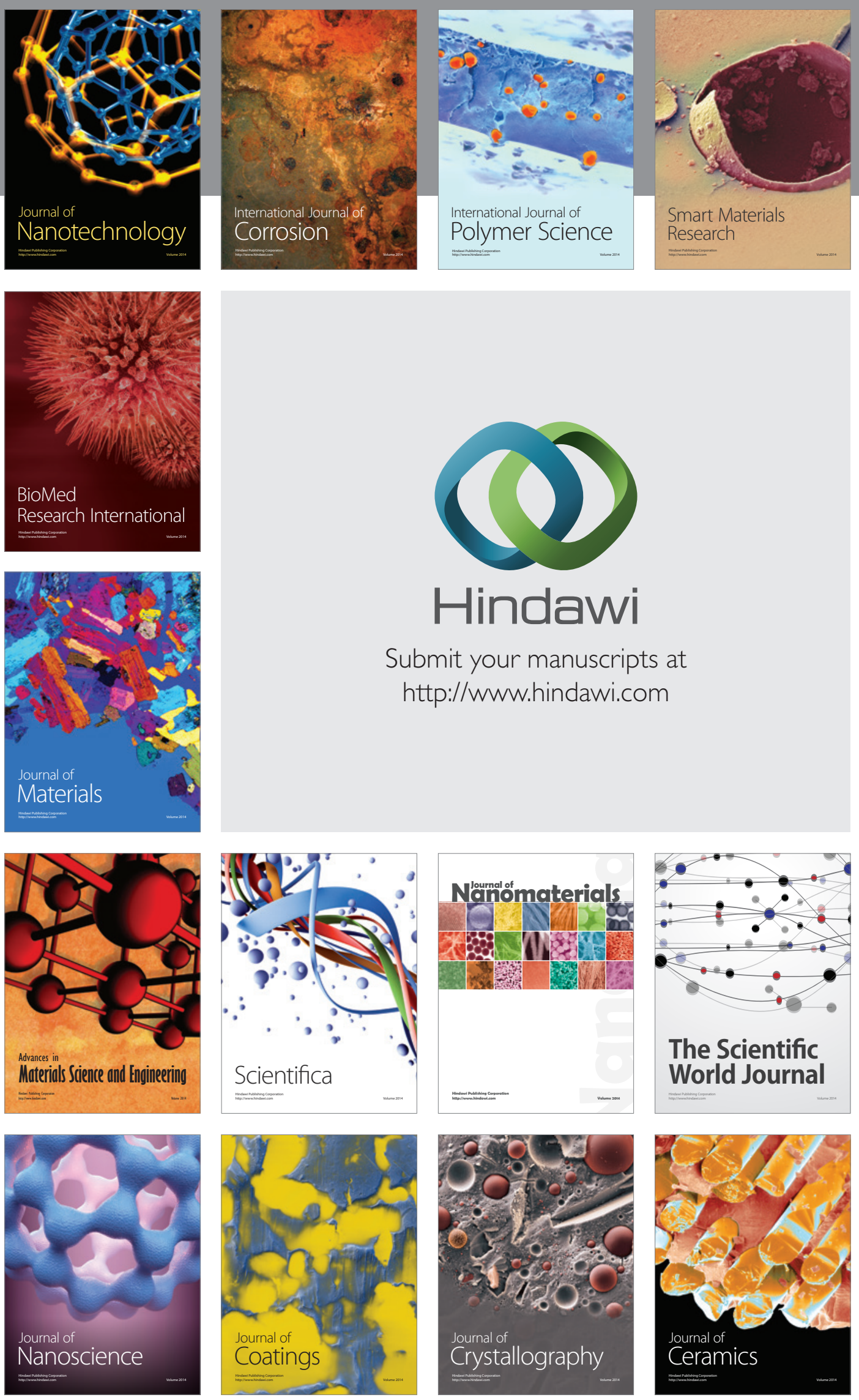

The Scientific World Journal

Submit your manuscripts at

http://www.hindawi.com

\section{World Journal}

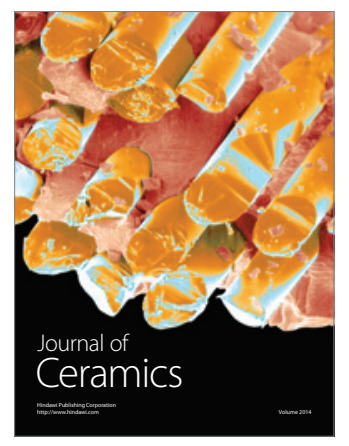

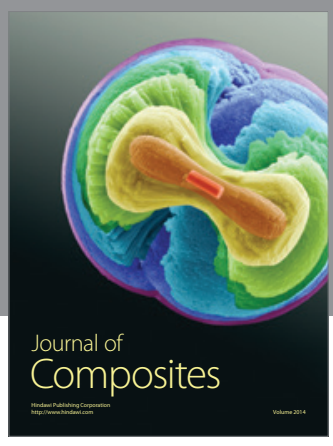
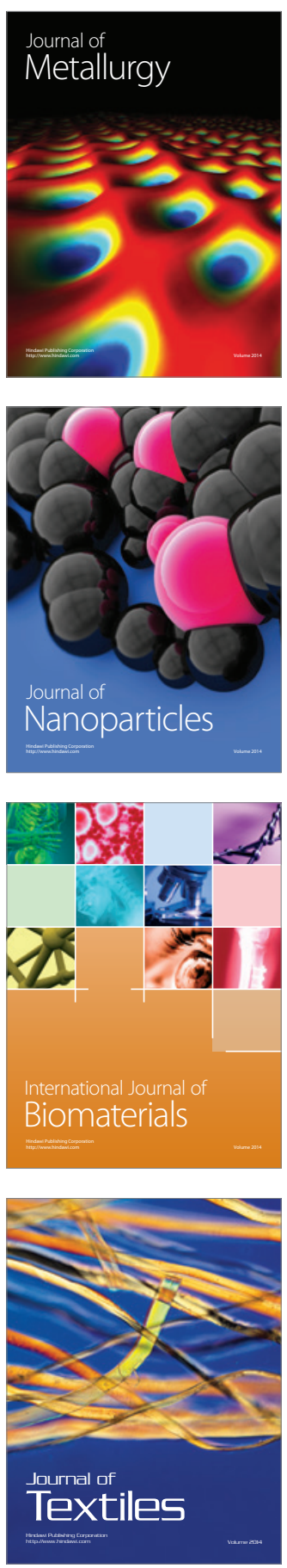